\title{
Association between poor glucose tolerance and rapid post natal weight gain in seven-year-old children
}

\author{
N. J. Crowther ${ }^{1}$, N. Cameron $^{2}$, J. Trusler ${ }^{1}$, I. P. Gray ${ }^{1}$ \\ ${ }^{1}$ Department of Chemical Pathology, South African Institute for Medical Research, University of the Witwatersrand Faculty of \\ Health Sciences, Johannesburg, South Africa \\ ${ }^{2}$ Department of Human Sciences, Loughborough University, Loughborough, England
}

\begin{abstract}
Summary A number of studies have shown that glucose tolerance falls with decreasing birth weight and that people with low birth weight and high body mass index (BMI) as adults are those at greatest risk of developing Type II (non-insulin-dependent) diabetes mellitus. No such studies have been carried out in African populations. Therefore we investigated the relation between glucose tolerance and birth weight in a group of 7-year-old black South Africans for whom longitudinal anthropometric data were available. Oral glucose tolerance tests (OGTTs) were carried out on 152 subjects and inverse correlations were found between birth weight and the total amount of insulin secreted during the first $30 \mathrm{~min}$ $(r=-0.19, p=0.04)$ and last $90 \mathrm{~min} \quad(r=-0.19$, $p=0.04$ ) of the oral glucose tolerance test and also between birth weight and the 30 min glucose concen-
\end{abstract}

trations $(r=-0.20, p=0.02)$. Children born with low birth weights but who had high weights at 7 years had higher insulin concentrations and indices of obesity compared with those with low birth weights and low weights at 7 years. There were also positive correlations between weight velocity and BMI $(r=0.24$, $p=0.02)$ and weight velocity and insulin resistance $(r=0.18, p=0.04)$ as measured using homeostasis model assessment (HOMA). Thus, low birth weight in conjunction with rapid childhood gains in weight especially as subcutaneous fat, produces poor glucose tolerance in 7-year-old children and can make them susceptible to the development of Type II diabetes later in life. [Diabetologia (1998) 41: 1163-1167]

Keywords Insulin, glucose, birth weight, weight velocity, insulin resistance.
Studies in Europe [1], India [3] and America [4] have shown that birth weight and weight at 1 year of age correlate with glucose tolerance. Thus, factors affecting birth weight and infant growth such as fetal and neonatal nutrition, seem to play a part in the aetiology of glucose intolerance and Type II (non-insulin-dependent) diabetes mellitus.

These findings have been used as supportive evidence for the 'thrifty phenotype' hypothesis [5] which

Received: 19 February 1998 and in revised form: 18 May 1998

Corresponding author: N.J. Crowther, Department of Chemical Pathology, South African Institute for Medical Research, University of Witwatersrand Faculty of Health Sciences, 7 York Road, Parktown 2193, Johannesburg, South Africa Abbreviations: OGTT, oral glucose tolerance test; HOMA, homeostasis model assessment. proposes that the fetus selectively apportions nutrients, 'channelling' them to essential organs such as the brain and heart during times of poor nutrition at the expense of peripheral organs like the pancreas. Poorer pancreatic development with a smaller complement of islet endocrine cells and, possibly, changes in tissue insulin sensitivity means that whilst a person remains in an environment where nutrients are scarce there is no adverse effect. When exposed to conditions of increased nutrition however, the pancreatic beta cell complement is unable to meet the biochemical demands and glucose intolerance and Type II diabetes can result. Those at greatest risk of developing Type II diabetes are those born with low birth weights who develop a high BMI [4].

The combination of low birthweight and subsequently high BMI is characteristic of populations undergoing cultural and economic shifts towards first- 
Table 1. Correlations between anthropometric measurements and concentrations of insulin, glucose and insulin resistance

\begin{tabular}{|c|c|c|c|c|}
\hline Measurements & 30 min insulin & 120 min insulin & 30 min glucose & Insulin resistance (HOMA) \\
\hline Birth weight & NS & NS & $\begin{array}{l}r=-0.20 \\
p=0.02 \\
(139)\end{array}$ & NS \\
\hline Height at age of 1 year & NS & NS & $\begin{array}{l}r=-0.19 \\
p=0.02 \\
(139)\end{array}$ & NS \\
\hline Height at age of 7 years & NS & NS & $\begin{array}{l}r=-0.22 \\
p=0.01 \\
(124)\end{array}$ & NS \\
\hline BMI at age of 7 years & $\begin{array}{l}r=0.40 \\
p<0.0001 \\
(115)\end{array}$ & $\begin{array}{l}r=0.27 \\
p=0.005 \\
(106)\end{array}$ & NS & $\begin{array}{l}r=0.24^{\mathrm{a}} \\
p=0.022 \\
(116)\end{array}$ \\
\hline Subscapular at age of 5 years & $\begin{array}{l}r=0.23 \\
p=0.009 \\
(128)\end{array}$ & NS & $\begin{array}{l}r=0.19 \\
p=0.024 \\
(138)\end{array}$ & NS \\
\hline Triceps at age of 5 years & $\begin{array}{l}r=0.22 \\
p=0.013 \\
(128)\end{array}$ & $\begin{array}{l}r=0.19 \\
p=0.043 \\
(108)\end{array}$ & $\begin{array}{l}r=0.21 \\
p=0.014 \\
(138)\end{array}$ & NS \\
\hline $\begin{array}{l}\text { Weight velocity between birth } \\
\text { and age of } 7 \text { years }\end{array}$ & $\begin{array}{l}r=0.36 \\
p<0.0001 \\
(126)\end{array}$ & $\begin{array}{l}r=0.30 \\
p=0.002 \\
(109)\end{array}$ & NS & $\begin{array}{l}r=0.18^{\mathrm{a}} \\
p=0.04 \\
(130)\end{array}$ \\
\hline
\end{tabular}

${ }^{a}$ Corrected for age and sex.

NS = No significant correlation.

Figures in parentheses are $n$ numbers

world standards [6]. This is the case in South Africa, where rural black populations are becoming increasingly urbanised [7]. In addition intra-uterine growth retardation is more common within the black population compared with that in the white [8]. According to the thrifty phenotype hypothesis this combination of factors should cause demonstrable changes in carbohydrate metabolism which could make this ethnic group more susceptible to Type II diabetes as adults.

We therefore studied the link between birth weight, growth rate and particular anthropometric indices and glucose tolerance in 7-year-old black South Africans.

\section{Subjects and methods}

This study was approved by the University of the Witwatersrand Committee for Research on Human Subjects (Medical) and the parents gave informed consent for their children to participate in the study.

The "Birth to Ten" study group contains 4029 participants [9]. A pure longitudinal cohort was selected from this group using the criteria of full-term birth, complete data for birth weight and weight and height at 1 and 5 years of age and black South African ethnicity. Of 468 subjects a statistically and logistically appropriate sample, in terms of size and representativeness, of 240 (1:1, boys:girls) subjects were randomly selected and field workers visited each of the chosen families to provide information about the study and to request participation.

The children were fasted for at least $10 \mathrm{~h}$ before the oral glucose tolerance test (OGTT). They were weighed and their heights measured. An anaesthetic cream was applied to the site of the decubitus vein and 30 min later a cannula was insert- ed. A fasting blood sample was taken and $1.75 \mathrm{~g} \cdot \mathrm{kg}^{-1}$ of glucose given to each child orally in the form of a Lucozade drink. Further blood samples were taken 30 and 120 min after the glucose load. Blood samples were immediately centrifuged and glucose concentrations measured on a Hitachi 717 autoanalyser using a glucose oxidase assay (Boehringer Mannheim, Mannheim, Germany). Serum samples for insulin were stored at $-70^{\circ} \mathrm{C}$ until assayed using an insulin-specific immuno-enzymetric assay (Medgenix, Fleurus, Belgium).

The sum of insulin concentrations during the course of the OGTT were calculated by integrating the 0,30 and $120 \mathrm{~min}$ time points. The sum of insulin concentrations during the first $30 \mathrm{~min}$ and during the last $90 \mathrm{~min}$ of the OGTT was calculated by integration of the fasting and $30 \mathrm{~min}$, and 30 and $120 \mathrm{~min}$ values respectively. Insulin resistance was calculated using the homeostasis model assessment (HOMA) [10].

Weight at birth and height, weight and subscapular and tricep skinfold thicknesses at the ages of 1,2, 4 and 5 years, and height and weight at 7 years of age as measured by standard procedures [11] were used in the current analysis.

Statistical analysis. The insulin data were skewed and were therefore logged prior to analysis. Pearson correlation and multiple regression analyses were carried out on the data.

\section{Results}

Of the 240 subjects who were asked to take part in the study 164 agreed to participate $(68 \%)$ of whom 152 (79 boys, 73 girls) gave one or more blood samples. The sub-sample was not significantly different from the parent cohort of 4029 subjects for any of the morphological characteristics being studied. 
Table 2. Anthropometric measurements and insulin concentrations in low birth weight, low weight at age 7 years subjects (group 1) and low birth weight, high weight at age 7 years subjects (group 2)

\begin{tabular}{lcc}
\hline Measurements & $\begin{array}{l}\text { GROUP 1 }(n=49) \\
\text { Low birth weight, } \\
\text { low weight at } \\
7 \text { years }\end{array}$ & $\begin{array}{l}\text { GROUP 2 }(n=27) \\
\text { Low birth weight, } \\
\text { high weight at } \\
7 \text { years }\end{array}$ \\
\hline Birth weight $(\mathrm{kg})$ & $2.7 \pm 0.3$ & $2.8 \pm 0.3$ \\
Weight at 7 $(\mathrm{kg})$ & $20.5 \pm 1.5$ & $24.4 \pm 1.7^{\mathrm{c}}$ \\
BMI at 7 $\left(\mathrm{kg} / \mathrm{m}^{2}\right)$ & $14.5 \pm 1.3$ & $15.7 \pm 0.9^{\mathrm{c}}$ \\
Tricep thickness at & $9.0 \pm 1.2$ & $10.5 \pm 2.3^{\mathrm{b}}$ \\
$5(\mathrm{~cm})$ & & \\
Subscapular thickness & $5.0 \pm 1.0$ & $6.0 \pm 1.9^{\mathrm{b}}$ \\
at 5 (cm) & $45.8 \pm 34.0$ & $52.8 \pm 41.8$ \\
Fasting insulin (pmol/l) & $305.8 \pm 108.2$ \\
30 min insulin $(\mathrm{pmol} / \mathrm{l})$ & $252.2 \pm 110.7$ & $137.2 \pm 82.3^{\mathrm{a}}$ \\
120 min insulin $(\mathrm{pmol} / \mathrm{l})$ & $94.1 \pm 56.8$ &
\end{tabular}

Values are means \pm SD

a $p<0.05$

$\mathrm{b} p<0.01$

${ }^{\mathrm{c}} p<0.0001$

Males and females were similar for all anthropometric measurements or derived indices except for height at 1 year of age when males were longer $(74.5 \pm 3.0 \mathrm{~cm}$ vs $72.7 \pm 3.0 \mathrm{~cm}, p=0.001)$.

Correcting for weight at 7 there was a negative correlation between birth weight and the integrated level of insulin during the first $30 \mathrm{~min}$ as well as during the last $90 \mathrm{~min}$ of the OGTT $(r=-0.19$, $p=0.043$ and $r=-0.19, p=0.037$ respectively). There was an inverse correlation between the 30 min glucose concentration and birth weight (Table 1) and, using multiple regression analysis, this remained significant following correction for weight at 7 years.

Height but not weight at 1 and 7 years of age (and height at 4 and 5 years of age) were inversely related to the $30 \mathrm{~min}$ glucose concentrations (Table 1) and remained so after correction for weight. All the height correlations with $30 \mathrm{~min}$ glucose levels were very similar.

At 7 years of age BMI correlated with the 30 and 120 min but not with the fasting insulin concentration (Table 1). Weight at 7 years also correlated with the $30 \mathrm{~min}(r=0.41, p<0.0001)$ and $120 \mathrm{~min}(r=0.30$, $p=0.002)$ insulin concentrations but height at 7 years did not. Both BMI and weight $(r=0.18, p=0.04)$ at the age of 7 years correlated with insulin resistance as assessed by HOMA when corrected for age and sex in a multiple regression analysis, but height did not.

Obesity as measured by skinfold thickness at the age of 5 years correlated with the $30 \mathrm{~min}$ and 120 min insulin concentrations and with that of the 30 min glucose (Table 1 ).
Weight velocity ( $\mathrm{kg}$ gained per year) between birth and 7 years of age correlated with HOMA when age and sex were included as independent variables in the multiple regression analysis (and also with $30 \mathrm{~min}$ and $120 \mathrm{~min}$ insulin concentrations [Table 1]). Weight velocities between the ages of 1 and 4, 4 and 5 and 5 and 7 years showed very similar correlations to those for weight velocity between birth and 7 years with the $30 \mathrm{~min}$ and $120 \mathrm{~min}$ insulin concentrations. Weight velocity between birth and 7 years also correlated with subscapular $(r=0.23, p=0.004)$ and triceps $(r=0.35, p<0.0001)$ skinfold thickness at age 5 years and with BMI at age 7 years $(r=0.90, p<$ $0.0001)$. None of the weight velocities significantly correlated with the glucose concentrations.

Weight tracking refers to the maintenance of a subject's weight within the same centile range over the period of study [12]. Two groups were created according to the tracking characteristics of weight from birth to 7 years (Table 2). Group 1 subjects are those whose birth weight and weight at 7 years are both in the lower 2 quartiles and Group 2 subjects have birth weight in the lower 2 quartiles and weight at 7 years in the upper 2 quartiles. Group 1 subjects had blood glucose concentrations which were not different from Group 2 subjects. The second group, however, had higher insulin concentrations, the 120 min insulin being statistically significantly higher. The group 2 subjects also had higher BMIs at 7 years of age and larger triceps and subscapular skinfold thicknesses at the age of 5 years than the group 1 subjects (Table 2).

\section{Discussion}

These data confirm results from other studies showing that glucose and insulin concentrations, in response to an oral glucose load, increase with declining birth weight $[1,3]$ showing that poor fetal growth can lead to insulin resistance later in life.

Catch-up and catch-down growth in response to low or high birth weights [13] are complete within the first 18 months of life and are unlikely to be a major factor in terms of growth over the first 7 years. Usually catch-up growth is characterised by slower growth velocity as the appropriate genetically-imprinted growth pathway is reached and the children begin to track. Children demonstrating the poorest glucose tolerance, however, have the greatest weight velocity which suggests that the programmed weight will be exceeded and eventually lead to obesity. The association between weight velocity between birth and 7 years of age and measures of subcutaneous fat and BMI were all significant by 5 years of age. Weight velocity also correlated with insulin resistance as assessed using HOMA [10]. Thus over-rapid weight gain can identify the child at risk of developing Type II diabetes later in life. This is further emphasised by 
the positive correlations between: skinfold thickness and plasma glucose and insulin concentrations; BMI and insulin concentrations and HOMA (Table 1), and from data showing that subjects who become obese during childhood are more likely to be obese as adults [14]. These people have a higher risk of developing Type II diabetes, obesity being strongly linked to the development of insulin resistance [15]. Furthermore, glucose and insulin concentrations at the age of 7 years correlate negatively with birth weight and positively with indices of obesity. Thus low birth weight in combination with obesity will produce poor glucose tolerance as shown in this study (Table 2).

Height, independent of weight is inversely related to glucose tolerance as reported by previous investigators [16]. Height at 7 years of age correlated with birth weight $(r=0.34, p<0.0001)$ and therefore the inverse association between height and glucose tolerance may again reflect poor fetal or neonatal nutrition since it is known that height is strongly influenced by events occurring in utero during early childhood [17]. Height shows a negative correlation with the 30 min glucose concentrations at all ages $(1,4.5$ and 7 years) studied. A stepwise, backward multiple regression analysis to control for co-linearity shows, however, that current height (height at 7 years) remains the only significant body size relationship $(r=-0.27, p=0.005)$. Naturally, current height incorporates the body size information from earlier heights and the negative relationship highlights the association of glucose intolerance with reduced height and therefore with stunting. Previous analyses have found that the prevalence of stunting in the population from which this sample was drawn has risen to $20 \%$ by 2 years of age [18]. This relatively high prevalence could indicate that this population is prone to a subsequently high incidence of Type II diabetes later in life. The prevalence of Type II diabetes within the black community is $5-6 \%$ and has increased over the past 20 years [19].

In summary, we show that children who could be at greatest risk of developing Type II diabetes are those who have low birth weights and subsequently gain weight rapidly between birth and 7 years. This is perhaps a result of poor nutrition in utero producing fetal biochemical adaptations which are then unsuited to an environment in which nutrition is greatly increased. These subjects have a tendency to be more insulin resistant possibly due to the combined effects of the fetal adaptations and increased adiposity during infancy. Furthermore, the high levels of both obesity [20] and intra-uterine growth retardation [8] within the black South African population may make this ethnic group particularly at risk of developing a high incidence of Type II diabetes in the future. Fetal and infant nutrition have an important influence on childhood glucose tolerance and future re- search must therefore be directed toward identifying the dietary factors that influence glucose tolerance and if and how these factors can be used to reduce the incidence of Type II diabetes.

Acknowledgements. We would like to thank Marketa Toman for carrying out the insulin assays, Sr Nomsa Ramela for taking the blood samples and the Birth to Ten research assistants and study participants who made this project possible. We would also like to thank Johnson + Johnson and SmithKline and Beecham for their donations. The Birth to Ten study receives financial and logistic support from: the Urbanisation and Health Programme of the Medical Research Council; the Anglo-American and DeBeers Chairman's Fund Educational Trust; the Centre for Science Development of the Human Sciences Research Council; the University of the Witwatersrand; Kentucky Fried Chicken; Liberty Life; Liqui-Fruit; Delmas Milling; Astra Pharmaceuticals and Suzuki. N. J. Crowther receives research funding from the South African Institute for Medical Research and from the South African Medical Research Council.

\section{References}

1. Hales CN, Barker DJP, Clark PMS et al. (1991) Fetal and infant growth and impaired glucose tolerance at age 64 . BMJ 303: 1019-1022

2. Lithell HO, McKeigue PM, Berglund L, Mohsen R, Lithell U-B, Leon DA (1996) Relation of size at birth to non-insulin-dependent diabetes and insulin concentrations in men aged 50-60 years. BMJ 312: 406-410

3. Yajnik CS, Fall CHD, Vaidya U et al. (1995) Fetal growth and glucose and insulin metabolism in four-year-old Indian children. Diabet Med 12: 330-336

4. Valdez R, Athens MA, Thompson GH, Bradshaw BS, Stern MP (1994) Birth weight and adult health outcomes in a biethnic population in the USA. Diabetologia 37: 624-631

5. Hales CN, Barker DJP (1992) Type 2 (non-insulin-dependent) diabetes mellitus: the thrifty phenotype hypothesis. Diabetologia 35: 595-601

6. Popkin BM, Richards MK, Montiero CA (1996) Stunting is associated with overweight in children of four nations that are undergoing the nutrition transition. J Nutr 126: 3009-3016

7. Rossi-Espagnet A, Goldstein GB, Tabibzadah I (1991) Urbanization and health in developing countries: a challenge for health for all. World Health Statistics Quarterly 44: 185-244

8. Cooper PA, Simchowitz ID, Sandler DL, Rothberg AD, Davies VA, Wainer S (1996) Prevalence of hyaline membrane disease in black and white low-birth-weight infants. S Afr Med J 84: 23-25

9. Richter LM, Yach D, Cameron N (1995) Enrolment into Birth to Ten (BTT): population and sample characteristics. Paediatr Perinat Epidemiol 9: 109-120

10. Matthews DR, Hosker JP, Rudenski AS, Naylor BA, Treacher DF, Turner RC (1985) Homeostasis model assessment: insulin resistance and b-cell function from fasting plasma glucose and insulin concentrations in man. Diabetologia 28: 412-419

11. Cameron N (1984) The measurement of human growth. Croom-Helm, London

12. Rolland-Cachera MF (1993) Body composition during adolescence: methods, limitations and determinants. Horm Res 39 [Suppl 3]: 25-40 
13. Prader A, Tanner JM, Von Harnack GA (1963) Catch-up growth following illness or starvation. J Paediatr 62: 646-659

14. Rolland-Cachera MF, Bellisle F, Deheeger M, Pequignot F, Sempe M (1990) Influence of body fat distibution during childhood on body fat distribution in adulthood: a two decade follow-up study. Int J Obes 14: 473-481

15. Kahn CR (1996) The role of obesity in diabetes mellitus. Curr Opin Endocr and Diabetes 3: 1-2

16. Brown DC, Byrne CD, Clark PMS et al. (1991) Height and glucose tolerance in adult subjects. Diabetologia 34: 531-533

17. Tanner J, Healey M, Lockhart R, MacKenzie J, Whitehouse R (1956) Aberdeen growth study I: the prediction of adult body measurements from measurements taken each year from birth to 5 years. Arch Dis Child 31: 372

18. Cameron N (1998) The relationship between stunting at two and growth from birth to five years in urban African children from Soweto. Am J Hum Biol 10: 118 (Abstract)

19. Bonnici F, Hough S, Huddle K (1997) Type II diabetes mellitus clinical guidelines at primary health care level. S Afr Med J 87 (part 3): 497-512

20. Steyn K, Jooste PL, Bourne L et al. (1991) Risk factors for coronary heart disease in the black population of the Cape Peninsula. The BRISK Study. S Afr Med J 79: $480-485$ 